\title{
Thermoplastic Blends Based on Poly(Butylene Succinate-co-Adipate) and Different Collagen Hydrolysates from Tanning Industry-Il: Aerobic Biodegradation in Composting Medium
}

\author{
Roberto Altieri $^{1}$ (I) $\cdot$ Maurizia Seggiani ${ }^{2} \cdot$ Alessandro Esposito $^{1} \cdot$ Patrizia Cinelli $^{2} \cdot$ Vitale Stanzione $^{1}$
}

Accepted: 15 February 2021 / Published online: 26 March 2021

(c) The Author(s) 2021

\begin{abstract}
Two different raw hydrolyzed collagens (HCs), by-products of the Tannery industry, were investigated in blends with a bioplastic, as poly(butylene succinate-co-adipate) (PBSA), for the production of thermoplastic items for possible applications in agriculture. Chemical characterization of selected PBSA/HC blends and phytotoxicity assays on garden cress seeds (Lepidium sativum L.), used as spy species, were carried out; in addition, biodegradation and disintegration of specimens were assessed under controlled composting conditions at different temperature $\left(58\right.$ and $25^{\circ} \mathrm{C}$ ). Although one of the $\mathrm{HC}$ investigated released sodium chloride in the aqueous extract, all PBSA/HC blends, up to $20 \mathrm{wt} \% \mathrm{HC}$, resulted no-phytotoxic and showed considerable amounts of macro- and micro- nutrients for plants (mainly nitrogen). Regardless the amount added, $\mathrm{HCs}$ enhanced the biodegradation rate of PBSA/HC blends in compost at $58{ }^{\circ} \mathrm{C}$ compared to pure PBSA; lowering the temperature at $25^{\circ} \mathrm{C}$, as expected, biodegradation rate slightly lowered using the same compost. Most disintegration tests, performed on dog bone samples, corroborated the results of the biodegradation tests, thus suggesting that plastic mixtures could reasonably end their life cycle in a composting facility without decreasing the quality and the safety of the resulting compost. The outcomes achieved encourage the use of raw collagen hydrolysates from tanning industry in the production of PBSA-based thermoplastic blends to produce compostable items (mulching films and/or plant pots) for more sustainable uses in agriculture and/or plant nurseries. In addition, the use of these low-cost by-products can lower the cost of final product and give it fertilizing properties for plants given the presence of organic nitrogen in the hydrolysates.
\end{abstract}

Keywords Poly(butylene succinate- $c o$-adipate $) \cdot$ PBSA $\cdot$ Hydrolyzed collagen $\cdot$ Aerobic biodegradation $\cdot$ Disintegration tests

\section{Introduction}

Plastic is a crucial and ubiquitous material in our daily lives. Over the past 50 years, the role and economic importance of plastics has consistently grown. Global production of plastics has increased more than 20-fold since the 1960s,

Roberto Altieri

roberto.altieri@cnr.it

$\triangle$ Maurizia Seggiani maurizia.seggiani@unipi.it

1 Institute for Agricultural and Forest Systems in the Mediterranean, Consiglio Nazionale Delle Ricerche, (ISAFOM-CNR), Via della Madonna Alta 128, 06128 Perugia, Italy

2 Department of Civil and Industrial Engineering, University of Pisa, Largo Lucio Lazzarino 2, 56126 Pisa, Italy reaching 359 million tons (Mt) in 2019 and it is expected to double again over the next 20 years (Source: European Bioplastics, nova-institute, 2019).

However, too often the way plastics are produced, used and discarded fails to capture the benefits of a typical "circular economy" approach and harms the environment: globally, 5-13 Mt of plastic waste end up in the oceans every year, causing growing public concern [1].

To face that, biodegradable plastics, specifically designed for short duration at their end-of-life, are seen as solution, although the global production capacity of biodegradable polymers still remains very low, about $1.16 \mathrm{Mt}$, corresponding to only $0.32 \%$ of the global plastic production (Source: European Bioplastics, nova-institute, 2019).

Besides, the introduction in the market of new plastics with enhanced biodegradable properties (expected to increase by $13.6 \%$ in the next five years), could even 
exacerbate the risk of release of micro-plastics into the environment, especially in the absence of clear labelling and marking for consumers proving their authentic biodegradability.

Biodegradation refers to decomposition of substances occurring with the prevalence action of microorganisms: it proceeds in several steps, including biodeterioration, biofragmentation and assimilation that finally lead to the recycle of carbon, the mineralization of organic compounds and the generation of new biomass.

Different standard methods have been defined to evaluate the biodegradability of plastics under different environment conditions. However, the unique proof that a plastic polymer, essentially consisting of an organic carbon skeleton, is consumed by microorganisms is its conversion into carbon dioxide; therefore, regardless of the inoculum used (compost, soil or water) the majority of methods involve measuring the carbon dioxide emitted during biodegradation in controlled environmental conditions [2, 3].

Among the biodegradable plastics suitable to replace conventional polyolefins, poly(butylene succinate-co-adipate) (PBSA), recently available on the market even of bio-based origin, is an interesting candidate because it shows good technological properties (i.e. melt processability) and, in addition, due to lower crystallinity and higher flexibility of polymer chains compared to poly-butylene succinate (PBS), enhanced biodegradability performance in different environments. In fact, several studies have demonstrated that films and molded items of PBSA significantly biodegraded within few months in soil, sea water and water enriched with activated sludge [4-8].

Unfortunately, the actual high cost of PBSA slows down its large use for commodity services: for this reason, in the last years, PBSA has been successfully blended with low cost natural polymers, such as corn starch $[6,9,10]$, to lower the cost of the final product, while ensuring a high biodegradability.

Similarly, and for the same purpose, waste protein hydrolysates, such as hydrolyzed collagen (HC), a typical by-product of the tannery industry, could be used in blend with bioplastics [11], given the well-known good adhesive properties of proteins and their good processability in the melt.

In the present study, PBSA/HC blends containing up to 20 wt.\% of HCs, obtained by alkaline and enzymatic hydrolysis of tanned leather shavings [12], were investigated in terms of their environmental sustainability. After a preliminary elementary characterization, PBSA/HC blends were assessed for their ultimate aerobic biodegradability under controlled composting conditions, simulating both "industrial" $\left(58^{\circ} \mathrm{C}\right)$ and "home" composting $\left(25^{\circ} \mathrm{C}\right)$. Moreover, disintegration tests of dog-bone specimens were carried out under composting, using a specific equipment [13] able to simulate on lab-scale a typical "industrial" process. Disintegration tests were also performed under "home" composting, at room temperature while the curing phase had been running.

\section{Materials and Methods}

\section{Materials}

Pellets of PBSA (tradename BioPBSTM FD92PM) were purchased from MCCP Germany GmbH (Mitsubishi Chemical Co., Tokyo, Japan). FD92PM is produced by copolymerization of bio-based succinic acid and adipic acid with 1,4-butanediol [14, 15], having a content of butylene adipate of about $20 \mathrm{wt} . \%$ [16]. This PBSA grade is certified industrial/home compostable and biodegradable in soil by TUV Austria [17]. Two types of HC were used for making PBSA/HC blends: one derived from alkaline hydrolysis of shavings, (HCa), supplied by Consorzio SGS (Santa Croce sull'Arno, Italy) and another derived from enzymatic hydrolysis of shavings (HCe), supplied by ILSA S.p.A. (Verona, Italy). Some chemical features of the two HC are reported in Table 1.

As reported in the concomitant study carried out by Seggiani et al. [12], PBSA/HC blends were prepared by melting extrusion and provided in different shapes (pellets, dog-bone specimens and films) for running investigations following described. Blends selected for testings were PBSA/HCe (80/20, w/w), PBSA/HCa (95/5) and PBSA/HCa (80/20).

\section{Chemical Characterization of PBSA/HCs Blends}

The ash content of samples, previously dried at $105{ }^{\circ} \mathrm{C}$ and reduced to size $<1 \mathrm{~mm}$, was determined as weight loss at $650{ }^{\circ} \mathrm{C}$ for $24 \mathrm{~h}$ in a muffle furnace. Total carbon,

Table 1 Properties of the HCs used in preparation of PBSA/HC blends (data provided by the suppliers)

\begin{tabular}{|c|c|c|}
\hline Property & $\mathrm{HCa}$ & $\mathrm{HCe}$ \\
\hline Dry matter (at $103{ }^{\circ} \mathrm{C}$, wt. $\%$ ) & 97.0 & 99.9 \\
\hline Ash (at $550{ }^{\circ} \mathrm{C}$, wt. $\% \mathrm{db}$ ) & 7.3 & $<1$ \\
\hline Bulk density (kg/L) & 0.50 & 0.55 \\
\hline Total nitrogen (wt.\% db) & 14.1 & 15.9 \\
\hline Organic nitrogen (wt.\% db) & 13.2 & 15.9 \\
\hline Organic carbon (wt.\% db) & 43.7 & 49.5 \\
\hline Organic matter (wt.\% db) & 87.4 & 99.0 \\
\hline $\mathrm{NaCl}$ (wt.\% db) & 7.8 & $<1$ \\
\hline Total amino acids (wt.\% db) & 88.9 & 99.0 \\
\hline Free amino acids (wt.\% db) & 39.7 & 0.6 \\
\hline $\mathrm{pH}$ in aqueous solution & 5.3 & 6.1 \\
\hline Water solubility $(1: 4, w / v)$ & Total & Almost total \\
\hline
\end{tabular}

$d b$ dry basis 
hydrogen, nitrogen and sulphur were determined on aliquots (50-100 mg) of samples, using a CHNS analyzer (Vario Macro Cube, Langenselbold, Germany). Electrical conductivity (EC) and $\mathrm{pH}$ were determined on deionized water extracts obtained after $24 \mathrm{~h}$ extraction $(1: 10 \mathrm{w} / \mathrm{v})$.

The elemental analysis was carried out on dry samples after acid digestion performed in a closed vessel microwave system (Ethos D, Milestone, Leutkirch im Allgäu, Germany), in accordance with the method US-EPA 3051A [18]; digested samples were then analyzed using Inductively Coupled Plasma-Optical Emission Spectrometry (ICP-OES) analyzer ICAPTM 7200 (ThermoFisher Scientific, Waltham, MA, USA).

\section{Biological Assays}

Germination tests on Lepidium sativum L. seeds were performed on composts used as inoculum in the ultimate aerobic biodegradation tests and on composts sampled after disintegration tests: these experiments were performed as described by Zucconi, et al. 1981 [19], adding deionized water on compost samples up to achieve $85 \%$ of water content (wet weight).

Furthermore, the same test was also used to check preliminarily if the release of salts in water, expected from the PBSA/HC blends (mainly in $\mathrm{HCa}$ ), could have a detrimental effect on the germination of $L$. sativum seeds. Test was conducted on water extracts $(1: 50 \mathrm{w} / \mathrm{v})$ of neat PBSA and selected PBSA/HCs blends, and on $\mathrm{HCe}$ and $\mathrm{HCa}$ water solutions $(1: 50 \mathrm{w} / \mathrm{v})$. Crushed pellets of neat PBSA and the selected PBSA/HCs blends were extracted with deionized water $(1: 50 \mathrm{w} / \mathrm{v})$ for $24 \mathrm{~h}$ using a horizontal shaker, and the water extracts, obtained by centrifugation and filtration through a $0.45 \mu \mathrm{m}$ membrane filter, were used as germination medium. A Whatman filter paper (no. 42), placed into $9 \mathrm{~cm}$ Petri dish, was wetted with $1 \mathrm{~mL}$ of extract and 9 seeds of $L$. sativum were placed on the paper. Deionized water was used as the control germination medium and five replicates were carried out for each sample. Petri dishes were wrapped with Parafilm $®$ to minimize water loss and allow adequate aeration, and kept in the dark for $42 \mathrm{~h}$ at $24{ }^{\circ} \mathrm{C}$. At the end of incubation, the number of germinated seeds and primary root lengths were measured and expressed as percentage of the Germination Index (GI) in the control. GI was calculated using the following equation:

$G I(\%)=\frac{G_{s} \cdot L_{s}}{G_{c} \cdot L_{c}} \times 100$

where $G_{s}$ and $G_{c}$ are the number of seeds germinated for the sample and for the control, respectively; $L_{s}$ and $L_{c}$ are the mean root lengths for the sample and for the control, respectively.

\section{Ultimate Aerobic Biodegradation Tests in Composting Conditions}

The biodegradability of neat PBSA and selected PBSA/ $\mathrm{HC}$ blends was evaluated according to the standard method UNI EN ISO 13,432 and 14,855-1 [20,21], using a specific Lab equipment, set up at ISAFOM-CNR and previously described [22].

About $20 \mathrm{~g}$ of $200 \mu$ - thick film sample, previously cut in small pieces $\left(<1 \mathrm{~cm}^{2}\right)$ by scissors, were kept at $58{ }^{\circ} \mathrm{C}$ (thermostatic chamber, Gallenkamp, UK) in $2 \mathrm{~L}$ airtight vessels (bioreactors) and exposed to about $240 \mathrm{~g}$ of wet inoculum (50\% water content), providing a constant $\mathrm{CO}_{2}$-free air flow rate of about $20 \mathrm{~L} / \mathrm{h}$ all along the test. Two InfraRed Gas Analyzer (IRGA) sensors were used for measuring the $\mathrm{CO}_{2}$ concentration in the exhausted air flowing over each vessel: Leybold-Heraeus Binos ${ }^{\circledR}$ (Germany), for levels below 3000 ppm, and Gascheck by Edinburgh Sensors (UK), for higher concentrations up to $100,000 \mathrm{ppm}$. An alternate measuring/cleaning sequence was ensured to properly monitor the $\mathrm{CO}_{2}$ concentration, recording up to six series of data per day.

The biodegradation test was conducted in triplicates, using an olive mill waste compost, obtained using the procedure reported in [23], as inoculum (blank) and cellulose powder (Sigmacell Type 20, $20 \mu \mathrm{m}$, Sigma-Aldrich) as certified biodegradable material (positive reference). The automation, monitoring, recording and elaboration of data were performed by a customized software developed in LabVIEW® environment.

Bioreactors were frequently shaken to stimulate and homogenize the biodegradation process, while the moisture content was estimated by weighting the vessels after shaking, and kept at about 50\% all over the test in order to ensure an ideal environment for microbes driving the biodegradation.

The biodegradation extent of each sample was calculated as percentage, corrected for the inoculum (blank) vessel emissions, of the overall theoretical amount of $\mathrm{CO}_{2}\left(\mathrm{Th}_{\mathrm{CO} 2}\right)$ that could be released, in case of complete mineralization, and calculated on the basis of the initial organic carbon content of the sample:

Biodegradation $(\%)=\frac{\sum C O_{2 \text { sample }}-\sum C O_{\text {2inoculum }}}{T h_{C O 2}} \times 100$

where $\mathrm{SCO}_{2}$ is the cumulative amount of $\mathrm{CO}_{2}$ evolved from the sample or inoculum all over the test.

In order to study "home" composting, the ultimate biodegradation test was repeated at $25^{\circ} \mathrm{C}$, using the same equipment and procedure above described, according to the Australian Standard AS 5810-2010 [24]. This standard requires that the test sample shall degrade at least $90 \%$ in 
total or equal to maximum degradation of a suitable reference substance (cellulose in this case).

\section{Disintegration Tests in Compost}

Dog-bone shaped specimens (length $90 \mathrm{~mm}$, max width $10 \mathrm{~mm}$; min. width $4.8 \mathrm{~mm}$; thickness $1.35 \mathrm{~mm}$, weight $1.2 \mathrm{~g}$ ), produced by injection molding using PBSA neat and selected PBSA/HCs blends [12], were subjected to the disintegration tests under simulated "industrial" composting conditions. Experiments were carried out using an automatic lab equipment, Composter (Figs. 1 and 2), recently designed and set up at CNR-ISAFOM [14], and mostly taking EN 14,045 as reference [25]. Composter includes two aerated and basically adiabatic $35 \mathrm{~L}$ bioreactors, able to reproduce and control an "industrial" composting process, characterized by typical sequence of mesophilic-thermophilic-mesophilic phases. It records in real time the temperature and weight of the biomass, and quantifies $\mathrm{O}_{2}$ consumption and $\mathrm{CO}_{2}$ emission resulted in the exhausted air from the aerobic biodegradation process driven by the microbial populations (mainly bacteria and fungi) colonizing the compost.

The organic mixture intended for running disintegration tests included organic waste (OW) such as: olive pomace (51\%), dry olive leaves and twigs (4\%), woodchips (14,5\%), wheat straw (5.5\%) and pig slurry (22\%). Moreover, about

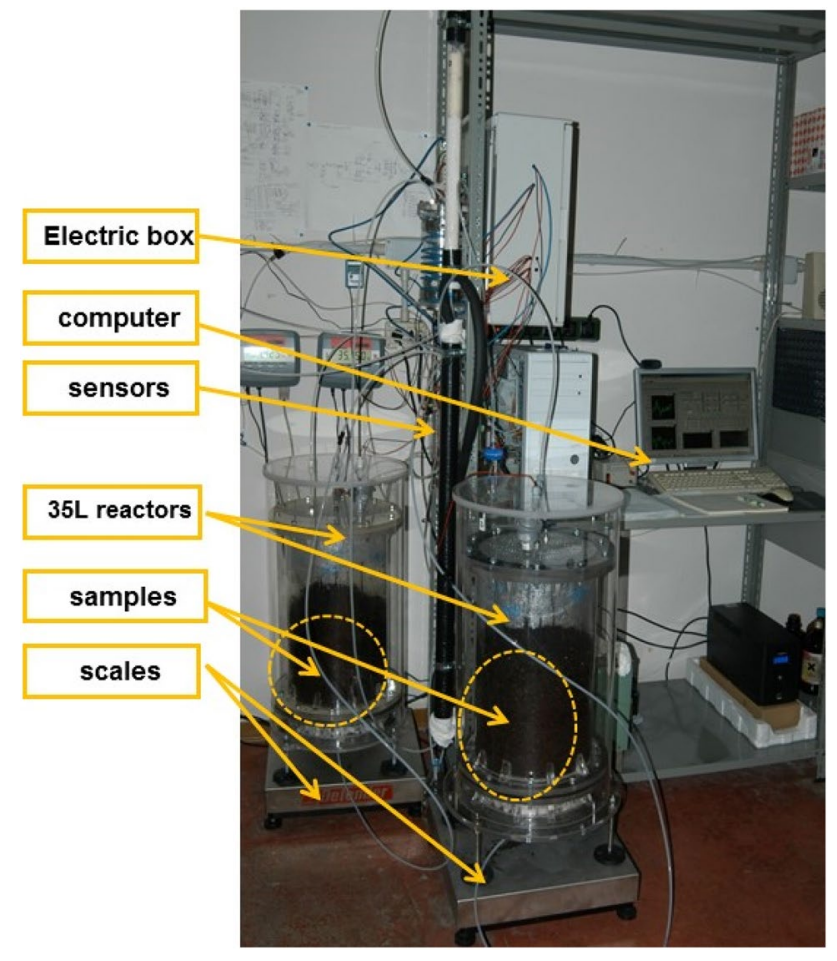

Fig. 2 Composter, lab-scale equipment arranged for assessing the disintegration degree of plastic specimens under "industrial composting" conditions

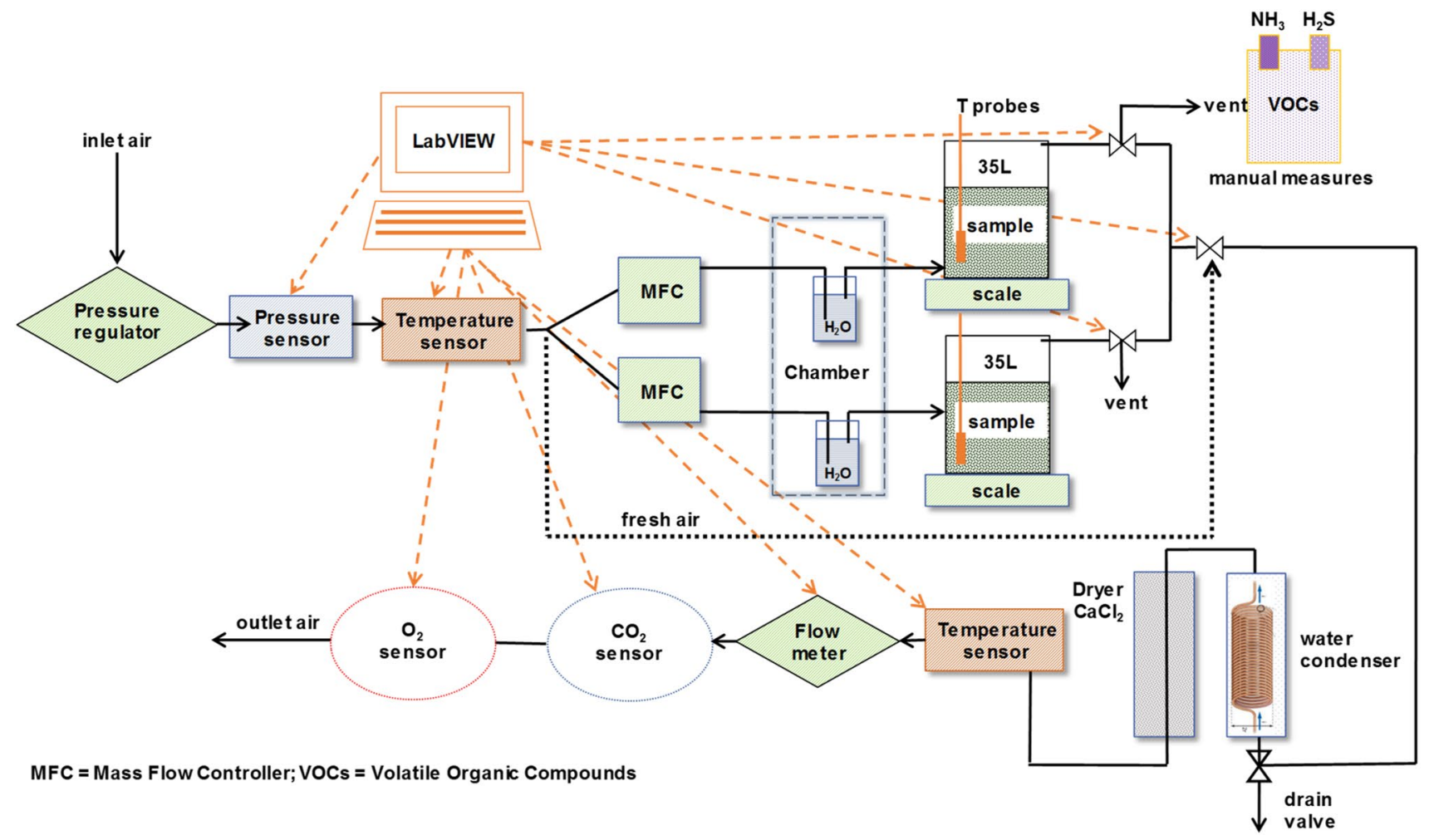

Fig. 1 Schematic diagram of the Composter 
3\% Etixamin, supplied by ILSA S.p.A. (Verona, Italy), was added for adjusting the $\mathrm{C} / \mathrm{N}$ ratio of the biomass. The starting OW mixture prepared for the test showed a $\mathrm{C} / \mathrm{N}=26.3$, moisture $=50.3 \%$, volatile solids content $=93.5 \%(\mathrm{w} / \mathrm{w})$, $\mathrm{pH}=5.5$. OWs were selected considering hygroscopic features, physical structure and $\mathrm{C} / \mathrm{N}$ ratio of each ingredient, measured out in order to get an ideal batch to compost. It is well-known that piles with a $\mathrm{C} / \mathrm{N}$ ratio ranging around 25-30, a moisture content 40-60 wt.\% and a balanced microand macro-porosity (bulk density around $0,5 \mathrm{~kg} \mathrm{~L}^{-1}$ ), compost in a right way. It usually results from an appropriate mixing of OW rich in water with others dry; in our case, wet olive pomace and pig slurry were mixed with hygroscopic bulking agents, such as wheat straw, woodchips and dry leaves. At the beginning each bioreactor was loaded with $11.7 \mathrm{~kg}$ of the batch described, and used for running disintegration tests.

The air flow rate of bioreactors is managed by two separate mass flow controller (Model F-201CV-10 K-AGD-22-V, $500 \ln \mathrm{h}^{-1}$, Bronkhorst ${ }^{\circledR}$ High Tech, NL) able to keep the oxygen concentration in the exhausted air above $10 \mathrm{vol} . \%$, thus ensuring a full aerobic biodegradation. Temperature of the biomass, pressure and temperature of the inlet and outlet airflows are monitored continuously during the trial, as well as weight loss of the bioreactors placed on scales. Concentrations of oxygen and carbon dioxide are recorded from the exhausted air by means of specific online gas detectors: zirconium dioxide oxygen sensor (model XYA5M, equipped with oxygen sensor circuit board ZBXYAF, FirstSensor, DE) and Gascheck $\mathrm{CO}_{2}$ Sensor (0-10 vol. $\left.\% \mathrm{CO}_{2}\right)$ by Edinburgh Sensors Ltd (UK). Acquisition of signals, control of actuators, remote software supervision, data elaboration and monitoring are performed by means of fit-for-purpose integration of hardware and software created in NI LabVIEW environment. Parameters are stored, plotted and promptly displayed in tables, graphs and spreadsheets, showing on video in real time trends of biodegradation occurring in both bioreactors. Without stopping data collection, bioreactors can be easily opened for turning the mixture, thus warranting a homogeneous biodegradation process. At the end of the thermophilic phase, which lasts 5-7 weeks, bioreactors are emptied and compost arranged in a pile kept at room temperature to allow the mesophilic phase to take place (compost curing), while ensuring an adequate moisture content (40-60 wt.\%) in the biomass up to the end of disintegration tests.

From the beginning, dog bone specimens were buried into the OW mixture loaded in the bioreactors in order to promote their biodegradation and disintegration, together with the rest of the biomass. Each type of specimen was placed into separate polyethylene (PE) net sacks ( $1 \mathrm{~mm}$ holes) for a successive easier recovery by sieving of the sample residues, likely reduced in small pieces. At the end of test lasted 84 days, visual assessments on dog-bone specimens were carried out for estimating the percentage of disintegration: a positive result occurs when the residual material with size higher than $2 \mathrm{~mm}$ is less than $10 \%$ of the initial mass weight. However, it was impossible to perform reliable weight loss assessments on dog-bone residues, due to an enhanced biodegradation occurred. Therefore, the degree of disintegration, as suggested by other authors [26], was estimated by measuring the area of plastic residues $>2 \mathrm{~mm}$, using ImageJ, a public domain Java image-processing program (https:// imagej.nih.gov/ij/). In that case, the thickness of fragments was not taken into account, although it appeared thinned if compared to the initial one; therefore, outcomes shall be considered underestimated, at least partially.

Disintegration in compost was also performed at room temperature, simulating "home" composting. Tests were carried out in buckets left indoor (Fig. 3) and different ingredients were utilized for making composts used as degradation media (Table 2). Six dog-bone specimens, for each PBSA/ $\mathrm{HC}$ blend, were buried in different compost and left to biodisintegrate for 259 days.

At the end of both disintegration tests, the potential phytotoxicity of composts, sampled in the surrounding area where dog-bone specimens disintegrated, were evaluated by germination test on cress, as described above in the Biological assays section.

\section{Results and Discussion}

\section{Chemical Characterization and Biological Assays}

Both solutions of $\mathrm{HCs}(1: 50, \mathrm{w} / \mathrm{v})$ showed high salinity, with higher values for $\mathrm{HCa}$, while PBSA revealed, as expected, low EC (Table 3). These data agreed with the intermediate values for salinity found on the PBSA/HC blend extracts, with higher values related to higher $\mathrm{HC}$ content.
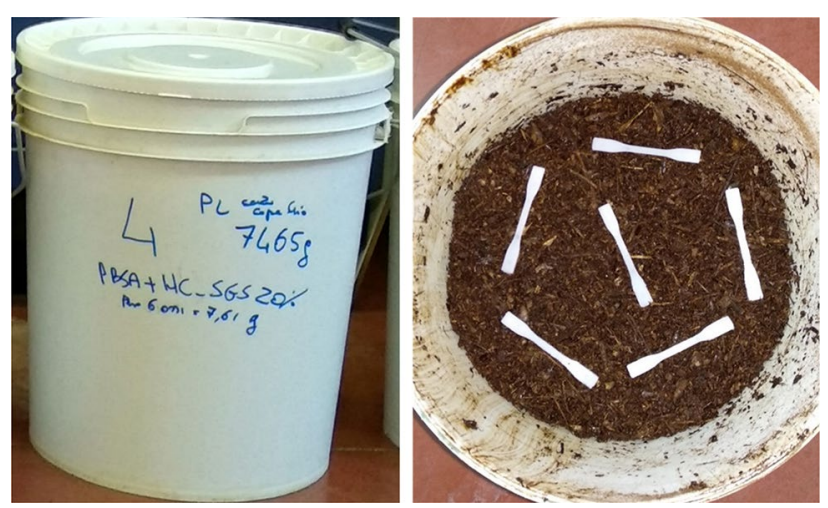

Fig. 3 Dog-bone specimens buried into compost kept indoor at room temperature, undergoing the mesophilic curing phase for the home composting disintegration test 
Table 2 Composition of composts used as biodegradation media in the "Home composting" disintegration test

\begin{tabular}{lllll}
\hline Sample & $\begin{array}{l}\text { PBSA } \\
\operatorname{mix} 1\end{array}$ & $\begin{array}{l}\text { PBSA/HCe 80/20 } \\
\operatorname{mix~2~}\end{array}$ & $\begin{array}{l}\text { PBSA/HCa 80/20 } \\
\operatorname{mix~3~}\end{array}$ & $\begin{array}{l}\text { PBSA/HCa 95/5 } \\
\operatorname{mix~4~}\end{array}$ \\
\hline $\begin{array}{l}\text { Compost components } \\
\text { Broadleaf prunings, \% }\end{array}$ & 43.7 & 22.1 & 43.5 & 15.0 \\
Conifer prunings, \% & 0.0 & 22.1 & 0.0 & 5.0 \\
Pig slurry, \% & 48.4 & 47.6 & 56.5 & 0.0 \\
Rabbit manure, \% & 4.7 & 4.8 & 0.0 & 0.0 \\
Chicken manure, \% & 3.1 & 3.4 & 0.0 & 0.0 \\
Olive husk, \% & 0.0 & 0.0 & 0.0 & 80.0 \\
Starting compost composition & & & & 43.6 \\
Carbon, \% dm & 45.5 & 45.4 & 46.9 & 1.0 \\
Nitrogen, \% dm & 1.3 & 1.5 & 1.2 & 43.6 \\
C/N & 34.0 & 31.2 & 39.0 & \\
\hline
\end{tabular}

$d m$ dry matter

\begin{tabular}{|c|c|c|c|c|c|c|c|}
\hline & \multirow[b]{2}{*}{ Unit } & \multirow[b]{2}{*}{ PBSA } & \multirow[b]{2}{*}{$\mathrm{HCe}$} & \multirow[b]{2}{*}{$\mathrm{HCa}$} & \multicolumn{3}{|l|}{ PBSA/HC } \\
\hline & & & & & HCe 20 wt. $\%$ & HCa 5 wt. $\%$ & HCa 20 wt. $\%$ \\
\hline $\mathrm{pH}$ & & 7.45 & 5.10 & 5.19 & 5.60 & 4.81 & 4.71 \\
\hline $\mathrm{EC}$ & $\begin{array}{l}\text { dS m }{ }^{-1} \\
\text { wt. db\% }\end{array}$ & 0.051 & 1.728 & 3.160 & 0.999 & 0.590 & 2.350 \\
\hline ash & & 0.05 & 4.27 & 6.13 & 0.72 & 0.19 & 1.07 \\
\hline $\mathrm{C}$ & & 56.67 & 45.73 & 42.08 & 54.47 & 56.02 & 53.81 \\
\hline $\mathrm{N}$ & & 0.53 & 16.54 & 14.41 & 3.50 & 0.68 & 2.89 \\
\hline S & & 0.01 & 0.35 & 0.65 & 0.08 & 0.02 & 0.08 \\
\hline $\mathrm{H}$ & $\mathrm{g} \mathrm{Mg}^{-1}$ & 6.99 & 7.06 & 7.59 & 7.20 & 7.05 & 7.01 \\
\hline $\mathrm{Na}$ & & 6.71 & 4840.1 & $17,670.6$ & 887.9 & 796.7 & 3712.4 \\
\hline $\mathrm{K}$ & & 26.9 & 608.9 & 724.2 & 137.29 & 103.31 & 241.3 \\
\hline $\mathrm{P}$ & & 185.5 & 8.33 & 3978.8 & 60.4 & 187.4 & 672.7 \\
\hline $\mathrm{Ca}$ & & 12.1 & 9832.7 & 2128.7 & 2007.2 & 399.3 & 476.6 \\
\hline $\mathrm{Fe}$ & & 2.69 & 1.64 & 72.1 & 3.47 & 6.88 & 29.5 \\
\hline $\mathrm{Mg}$ & & 30.0 & 37.2 & 158.4 & 31.9 & 41.9 & 63.9 \\
\hline $\mathrm{Cu}$ & & 0.28 & 0.80 & 0.80 & bdl & 0.66 & 4.4 \\
\hline $\mathrm{Zn}$ & & 0.32 & 2.32 & 59.30 & 0.68 & 6.58 & 18.4 \\
\hline $\mathrm{Al}$ & & 0.94 & 7.37 & 10.72 & 2.08 & 3.24 & 6.4 \\
\hline $\mathrm{Pb}$ & & bdl & bdl & bdl & 0.25 & 0.10 & 0.12 \\
\hline $\mathrm{Cr}$ & & bdl & 10.43 & 37.39 & 1.98 & 1.67 & 8.58 \\
\hline $\mathrm{Mn}$ & & 0.03 & 0.72 & 4,74 & 0.22 & 0.27 & 0.96 \\
\hline $\mathrm{Ni}$ & & bdl & 0.85 & 1.15 & 1.24 & bdl & bdl \\
\hline Mo & & 0.09 & 0.70 & 0.29 & 0.15 & 0.24 & 0.38 \\
\hline As & & 0.45 & 0.24 & 0.19 & 0.52 & bdl & bdl \\
\hline Cd & & bdl & 0.03 & 0.01 & bdl & 0.04 & 0.05 \\
\hline GI & $\%$ & 114.0 & 75.4 & 39.9 & 82.9 & 92.1 & 67.3 \\
\hline
\end{tabular}

$d b$ dry basis, $b d l$ below detection limit; $\mathrm{pH}, \mathrm{EC}$ and GI determined on 1:50 (w/v) solutions for HCe and $\mathrm{HCa}$
Ash analyses corroborated these findings: in fact, $\mathrm{HCa}$ and related blends showed higher values, while PBSA neat showed a negligible ash content.
As regard pH, PBSA solution resulted nearly neutral, while both $\mathrm{HC}$ solutions showed a sub-acidic reaction, also confirmed in the PBSA/HC blends. 
Given the HCs origin [12], CNHS analyses proved a relevant content of nitrogen in the pure HCs (about 15\%), confirming data provided by the suppliers (Table 1). Consequently, higher nitrogen content resulted in the blends containing higher content of $\mathrm{HCs}$, up to $3.5 \mathrm{wt} \% \mathrm{~N}$ for PBSA/HCe 80/20 (wt $\% / w t \%$ ) (Table 3). Since nitrogen, as a key nutrient supply, usually boosts either microbial or plant growth, it can be assumed that the addition of HCs to the bioplastic can positively influence its biodegradation rate as well as the release of nitrogen, acting as fertilizer, provided that these mixtures end up in the growth media/ soil for plants.

ICP-OES analyses showed a relevant content of $\mathrm{Na}$ in both $\mathrm{HCs}$, with values for $\mathrm{HCa}$ more than 3 times higher than those for $\mathrm{HCe}$. Most of Na derives from the salted skins used in the tanning process. As for $\mathrm{N}, \mathrm{Na}$ content was found in the PBSA/HCs blends as a function of the amount of HCs added in the blend. Moreover, the high water solubility of $\mathrm{Na}$ salts is responsible for the high EC (salinity) showed in both HCs solutions and related PBSA/HCs blends. This feature could be of detrimental effect on plant growth when $\mathrm{Na}$ is released directly into the growth media. However, in case of excess, Na could be easily removed by leaching irrigations because it is weakly bonded on soil/growth media colloids [27].

In addition to N, ICP-OES analyses revealed interesting amounts of other nutrients for plants, such as $\mathrm{Ca}$ (mainly in $\mathrm{HCe}$ ), $\mathrm{P}$ (mainly in $\mathrm{HCa}$ ), $\mathrm{Mg}$ and $\mathrm{K}$ in both HCs and related PBSA/HCs blends, while some micronutrients, such as $\mathrm{Fe}, \mathrm{Cu}, \mathrm{Zn}, \mathrm{Mn}, \mathrm{Mo}$, even at low content, were found still within detectable values. Besides, it is worth noting that all checked heavy metals $(\mathrm{Ni}, \mathrm{Cd}, \mathrm{Pb}$, $\mathrm{Cr}$, As) resulted largely below limits required by the UNI EN ISO 13,432 standard [20]. Only Cr (total) in the pure $\mathrm{HCa}$, appeared rather high but, even when loaded in the blends at the highest rate (PBSA/HCa 20\%), Cr resulted $8.58 \mathrm{mg} \mathrm{kg}^{-1}$, more than five times lower than the maximum admitted limit $\left(50 \mathrm{mg} \mathrm{kg}^{-1}\right)$.

The GI values confirmed the potential safety for plants of the PBSA/HCs blends, even regardless the amount HCs added: in fact, all tested blends, as well as PBSA neat and HCe, showed GI \% higher than $60 \%$, threshold limit considered safe for water extracts obtained from compost [28]. Potential harmful GI was only found for the HCa solution (about $40 \%$ ), probably due to the high salinity that may inhibit the germination of seeds and/or the growth of the primary roots in the spy species tested (L. sativum L.).

Summarizing from an agronomic point of view, in case PBSA/HCs blends ended up in soil/growth media for plants, the resulting positive outcomes arising from the biodegradation could reasonably overcome potential drawbacks.
Table 4 Characterization of compost used as inoculum in the ultimate aerobic biodegradation tests

\begin{tabular}{lll}
\hline & Unit & Value \\
\hline $\mathrm{pH}$ & - & 8.06 \\
$\mathrm{EC}$ & $\mathrm{dS} \mathrm{m}{ }^{-1}$ & 2.960 \\
& wt.\% & \\
ash & & 26.08 \\
$\mathrm{GI}$ & & 69.00 \\
$\mathrm{C}$ & & 38.17 \\
$\mathrm{~N}$ & & 3.97 \\
$\mathrm{C} / \mathrm{N}$ & - & 9.61 \\
\hline
\end{tabular}

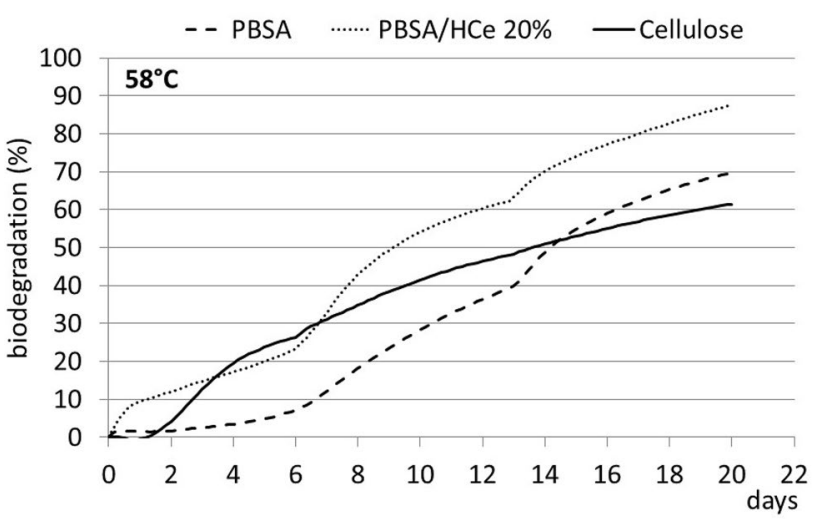

Fig. 4 Ultimate aerobic biodegradability of PBSA and PBSA/HCe $20 \%$ blends conducted under controlled industrial composting conditions (UNI EN ISO $14,855-1$, at $58^{\circ} \mathrm{C}$ )

\section{Ultimate Aerobic Biodegradation in Composting Medium}

The main chemical and biological features of the compost used as inoculum in biodegradation tests, are reported in Table 4 compost shows $\mathrm{pH}$ and $\mathrm{EC}$ values typical of mature products, with a GI\% higher than $60 \%$ which certifies its safety. In addition, the nitrogen abundance $(\mathrm{C} / \mathrm{N}<20)$ makes it a perfect substrate for stimulating microbial growth, thus allowing ideal biodegradation tests.

The first biodegradability test, conducted at $58{ }^{\circ} \mathrm{C}$, showed after 20 days cumulated emissions of $47.9 \pm 5.6$ and $54.0 \pm 2.5 \mathrm{gCO}_{2}$ per vessel, in PBSA and PBSA/HCe 20\%, respectively, corresponding to $69.7 \pm 13.6$ and $87.5 \pm 6.4 \%$ of biodegradation (Fig. 4).

In the second test at $58^{\circ} \mathrm{C}$, after 20 days, cumulated emissions of $38.6 \pm 10.5$ and $40.2 \pm 1.9 \mathrm{gCO}_{2}$ per vessel were recorded in PBSA/HCa $5 \%$ and PBSA/HCa $20 \%$, respectively, corresponding to $74.3 \pm 28.5$ and $81.8 \pm 5.5 \%$ of biodegradation (Fig. 5).

Analyzing outcomes from the positive reference (cellulose), both tests conducted at $58^{\circ} \mathrm{C}$ showed little differences between vessels (less than $20 \%$ in terms of biodegradation), satisfying the conditions required by the UNI EN 14,855-1 


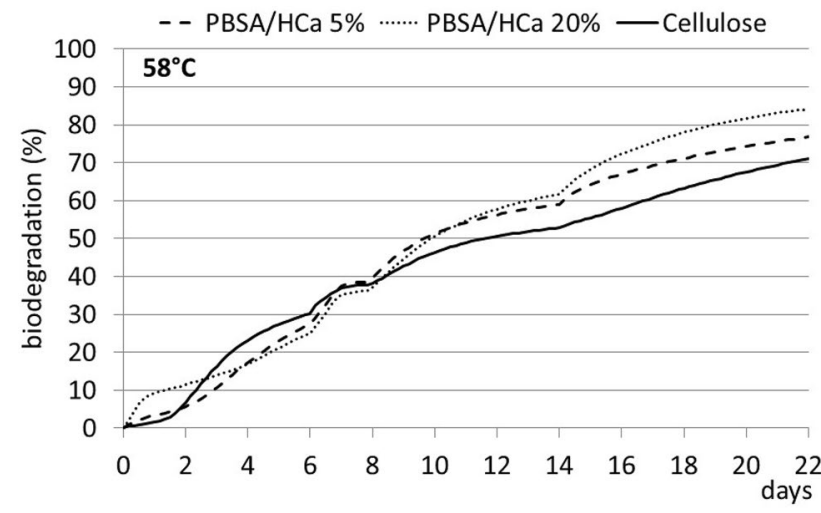

Fig. 5 Ultimate aerobic biodegradability of $\mathrm{PBSA} / \mathrm{HCa} 5 \%$ and PBSA/HCa $20 \%$ blends conducted under controlled industrial composting conditions (UNI EN ISO $14,855-1$, at $58^{\circ} \mathrm{C}$ )

standard. In fact, cumulated emissions of $39.0 \pm 2.4$ and $31.0 \pm 2.5 \mathrm{gCO}_{2}$ per vessel, corresponding to $61.4 \pm 7.5$ and $67.6 \pm 8.7 \%$ biodegradation, were recorded for cellulose in the first and second test, respectively, corresponding to $12.2 \%$ and $12.9 \%$ as CV (coefficient of variability). Moreover, also the inoculum complied with the 14,855-1 standard which requires the release of $50-150 \mathrm{mg}$ of $\mathrm{CO}_{2}$ per gram of VS (volatile solids) after ten days of incubation; indeed, inoculum alone (blank vessels) emitted $153.8 \mathrm{mg} \pm 6.1$ and $104.1 \mathrm{mg} \pm 7.3$ of $\mathrm{CO}_{2}$ per gram of VS, in the first and second biodegradation test, respectively.

Figures 4 and 5 show fast biodegradation rates from the beginning for all specimens tested, especially for blends with higher HC content. The presence of amino acids in both HCs enhanced the nitrogen availability for the microbes colonizing the inoculum so that they were stimulated to growth rapidly and use PBSA as carbon source, thus resulting in a quick biodegradation. It must be emphasized the fact that the high EC found in both $\mathrm{HCs}$ and consequent release of Na salts in the media-inoculum, did not affect negatively the biodegradation process. On the other hand, also pure PBSA, tested at $58{ }^{\circ} \mathrm{C}$, reached $70 \%$ of biodegradation in very short time (about 20 days), thus fully accomplishing the 14,588-1 standard, and showing, like PBSA/HCs blends, even higher biodegradation rates than cellulose (positive reference). It can be seen that after 20 days of incubation at $58{ }^{\circ} \mathrm{C}$, the biodegradation percentage found for PBSA and cellulose have been significantly higher than those reported by other authors in similar tests [29].

The results of the biodegradation tests carried out at $25{ }^{\circ} \mathrm{C}$, are reported in Fig. 6 e 7. In the first test, after 55 days, cumulated emissions of $36.6 \pm 1.5$ and $26.5 \pm 4.2$ $\mathrm{gCO}_{2}$ per vessel were recorded in PBSA and PBSA/ $\mathrm{HCe} 20 \%$, respectively, corresponding to $71.7 \pm 3.7$ and $48.4 \pm 10.1 \%$ of biodegradation (Fig. 6). In the second test, after 55 days, cumulated emissions of $29.3 \pm 0.6$ and

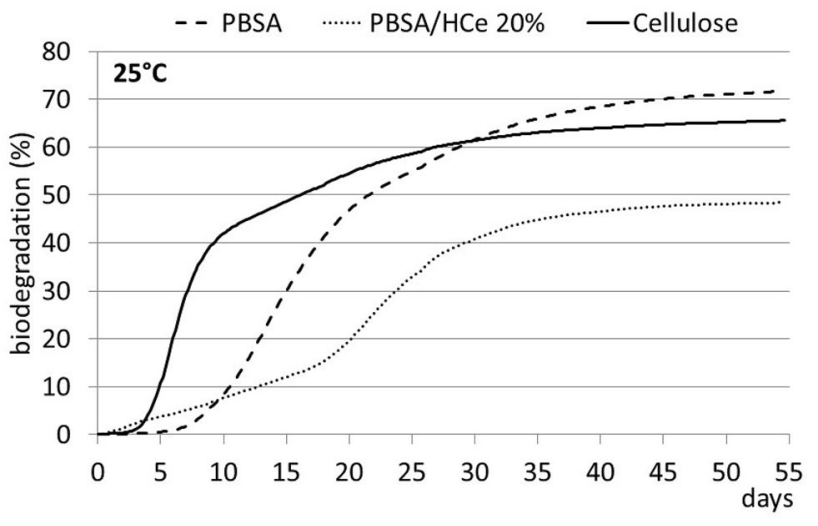

Fig. 6 Ultimate aerobic biodegradadation of PBSA and PBSA/HCe $20 \%$ blends conducted under controlled composting conditions (Australian standard $5810 / 2010$, at $25^{\circ} \mathrm{C}$ )

$23.9 \pm 2.8 \mathrm{gCO}_{2}$ per vessel were recorded in PBSA/HCa $5 \%$ and PBSA/HCa $20 \%$, respectively, corresponding to $70.9 \pm 1.7$ and $56.6 \pm 8.6 \%$ of biodegradation (Fig. 7).

Looking at the biodegradation of cellulose triplicates conducted at $25{ }^{\circ} \mathrm{C}$, as it happened at $58{ }^{\circ} \mathrm{C}$, the difference between vessels was always less than $20 \%$, as CV \%. In fact, cumulated emissions of $28.4 \pm 3.5$ and $20.8 \pm 1.9$ $\mathrm{gCO}_{2}$ per vessel, corresponding to $65.5 \pm 11.1(\mathrm{CV} \%=16.9)$ and $56.9 \pm 7.1(\mathrm{CV} \%=12.5)$, as \% biodegradation, were recorded in the first and second test, respectively.

Regarding $\mathrm{CO}_{2}$ emissions from the blank vessels loaded with the inoculum alone, the amount of $\mathrm{CO}_{2}$ recorded was $20.4 \pm 2.7$ and $33.0 \pm 4.0 \mathrm{mg}$ of $\mathrm{CO}_{2}$ per gram of VS, in the first and second test at $25^{\circ} \mathrm{C}$, respectively.

Tests carried out at $25^{\circ} \mathrm{C}$ corroborated findings achieved at $58{ }^{\circ} \mathrm{C}$ showing that most of the bio-based plastic biodegrades quite rapidly even at lower temperature. In fact, they all showed a biodegradability comparable to that of the reference material (cellulose) in the same period of time

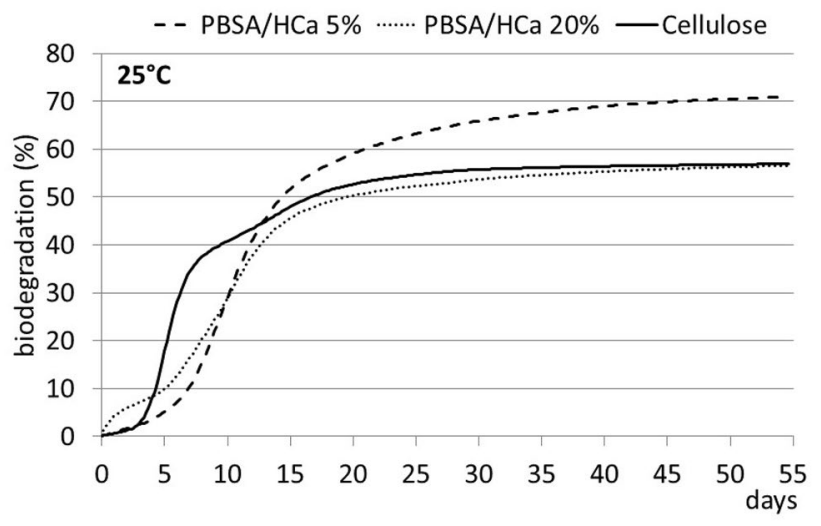

Fig. 7 Ultimate aerobic biodegradation of PBSA/HCa 5\% and PBSA/ $\mathrm{HCa} 20 \%$ blends conducted under controlled composting conditions (Australian standard 5810/2010, at $25^{\circ} \mathrm{C}$ ) 
(55 days); only the PBSA/HCe $20 \%$ blend showed a biodegradability lower than $90 \%$ relative to the cellulose reference. The lower biodegradation rate showed by the PBSA/ HCe 20\%, compared to neat PBSA and PBSA/HCa blends, can be reasonable attributed to the still present secondary structure of the HCe, as reported by Seggiani et al. [12], as well as a negligible content of free amino acids (Table 1), which can make the protein material of the blend less attackable by mesophilic microorganisms operating at such low temperatures.

As regards inoculum, comparing trends of biodegradation at different temperatures, it results that the temperature strongly affects the biodegradation rate. In fact, inoculum alone showed, at $58{ }^{\circ} \mathrm{C}$, a respiration rate, expressed as $\mathrm{mg}$ $\mathrm{CO}_{2}$ evolved per gram of volatile solids, 4.8 and 3.8 times higher than that registered at $25^{\circ} \mathrm{C}$, after 10 and 20 days, respectively (Table 5). On the other hand, analyzing the biodegradation trends for vessels added with bioplastics or reference material (cellulose), it results that higher temperature mainly boosts the process in the first period of biodegradation, especially for the bioplastic specimens. Indeed, cellulose showed at $58{ }^{\circ} \mathrm{C}$, as respect to $25^{\circ} \mathrm{C}$, only a little increase in biodegradation rate $(10-20 \%)$ while, after 10 days at $58{ }^{\circ} \mathrm{C}$, PBSA, PBSA/HCe 20\%, PBSA/ $\mathrm{HCa} 5 \%$ and $\mathrm{PBSA} / \mathrm{HCa} 20 \%$ showed a biodegradation rate $3.4,7.1,1.8$ and 1.8 times higher than those performed at $25{ }^{\circ} \mathrm{C}$, respectively. In addition, these differences tend to reduce over time as shown in Table 6 . The reasons of such behavior could be explained with the fact that microbial populations colonizing the inoculum may need some time to familiarize themselves with a new carbon source, as that contained in the bio-based plastics. On the other hand, cellulose represents a well-recognized food for all microbes and does not require any period of adaptation; therefore, it is rapidly metabolized from the beginning, regardless of the temperature.

\section{Disintegration Tests in Compost}

Figure 8 shows the weight loss and temperature of compost during the first phase of disintegration tests carried out

Table 5 Cumulated $\mathrm{CO}_{2}$ emission released by the inoculum after 10 and 20 days of incubation at $25^{\circ} \mathrm{C}$ and $58{ }^{\circ} \mathrm{C}$ (mean values from ultimate aerobic biodegradation tests)

\begin{tabular}{|c|c|c|}
\hline Temperature & $25^{\circ} \mathrm{C}$ & $58^{\circ} \mathrm{C}$ \\
\hline \multicolumn{3}{|c|}{$\mathrm{mg} \mathrm{g}^{-1} \mathrm{VS}$} \\
\hline Mean $\mathrm{CO}_{2},-10$ days & 26.7 & 129.0 \\
\hline Mean $\mathrm{CO}_{2},-20$ days & 46.4 & 176.8 \\
\hline
\end{tabular}

$V S$ volatile solids
Table 6 Biodegradation (\%) recorded after 10 and 20 days of incubation at $25{ }^{\circ} \mathrm{C}$ and $58{ }^{\circ} \mathrm{C}$ (ultimate aerobic biodegradation tests)

\begin{tabular}{lrll}
\hline Sample/Temperature & $25{ }^{\circ} \mathrm{C}$ & $58{ }^{\circ} \mathrm{C}$ & $\begin{array}{l}58{ }^{\circ} \mathrm{C} / \\
25^{\circ} \mathrm{C} \\
\text { (ratio) }\end{array}$ \\
\hline Cellulose-10 days & 41.4 & 44.0 & 1.1 \\
Cellulose-20 days & 53.6 & 64.5 & 1.2 \\
PBSA-10 days & 8.4 & 28.3 & 3.4 \\
PBSA-20 days & 46.9 & 69.7 & 1.5 \\
PBSA/HCe 20\%-10 days & 7.7 & 54.1 & 7.1 \\
PBSA/HCe 20\%-20 days & 19.7 & 87.6 & 4.4 \\
PBSA/HCa 5\%-10 days & 29.1 & 51.3 & 1.8 \\
PBSA/HCa 5\%-20 days & 59.1 & 74.3 & 1.3 \\
PBSA/HCa 20\%-10 days & 28.8 & 50.6 & 1.8 \\
PBSA/HCa 20\%-20 days & 50.3 & 81.8 & 1.6 \\
\hline
\end{tabular}

under "industrial composting" conditions simulated by the Composter.

Having used an ideal OW mixture for composting, mass loaded in the biorectors started to self-heat very soon, showing an intense microbial activity from the beginning: temperature reached high values in less than 1 day, thus soon entering the thermophilic phase that proceeded for about 30 days. In the meantime, at test day 20th, in order to prevent parts of the biomass from drying out or showing an excess of moisture, without disturbing data logging, bioreactors were opened and the content thoroughly mixed. This action resulted in peaks of oxygen consumption and related carbon dioxide emissions, as reported in Fig. 9, as well as further rapid increase in temperature of the pile (Fig. 8) due to an intense revitalized microbial activity that releases heat in the biomass.

The thermophilic phase of composting lasted about 30 days giving the way to the mesophilic phase, partially

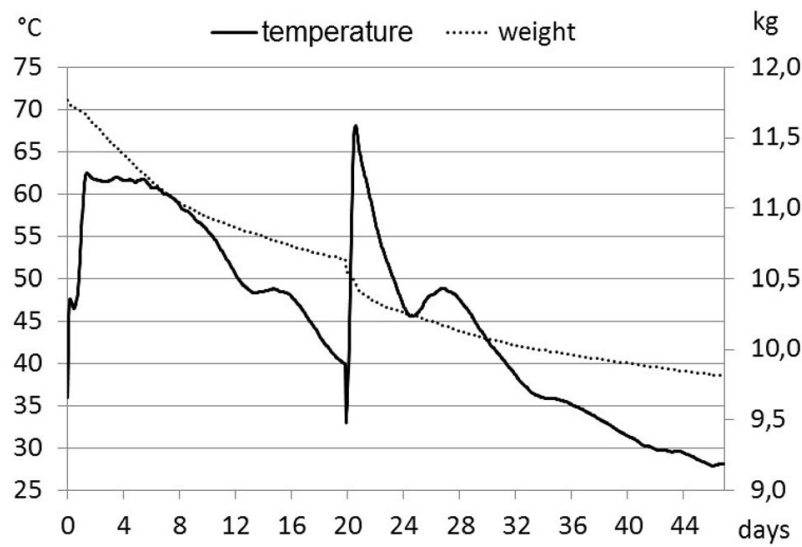

Fig. 8 Temperature and weight of compost during the first phase (45 days) of industrial composting disintegration test conducted in Composter 


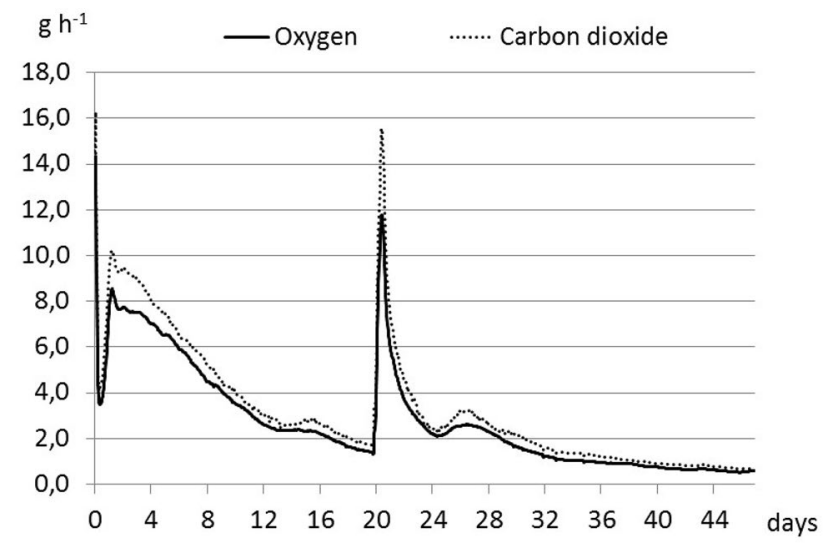

Fig. $9 \mathrm{O}_{2}$ consumption and related $\mathrm{CO}_{2}$ emission released from each bioreactor during the first phase (45 days) of industrial composting disintegration test conducted in Composter

carried out into the bioreactors (up to 45th day); later on, both bioreactors were emptied and the OW mixture left to compost in a tank (Fig. 10) at room temperature $\left(23.8 \pm 3.3{ }^{\circ} \mathrm{C}\right)$ up to the end of disintegration test $(84$ th day). At this stage, residues of plastic specimen, if any, have been pulled out from compost for visual inspections and for assessing the extent of disintegration occurred.

An intermediate visual assessment, done after 20 days, evidenced clear signs of disintegration in all specimens under investigation, with particular reference to the neat PBSA ones, which showed clear breaks in their structure (Fig. 11).

Figure 12 depicts residues of plastic specimens pulled out from compost after 84 days of disintegration test, while Table 7 reports the extent of disintegration estimated.

According to the reference taken into account [25], only PBSA/HCe 20\% dog-bone specimens showed positive findings, with \% residues larger than $2 \mathrm{~mm}$ below the threshold limit admitted (10\%). All other specimens did not pass the test, even though residues showed evident signs of degradation and resulted extremely fragile to the touch.

Phytotoxic test, conducted on compost sampled in the area (net bags, Fig. 10) where specimens disintegrated, confirmed the absence of potential detrimental effects caused by the biodegradation of bioplastics; in fact, they all showed GI values (Table 7) largely above the threshold limit (60\%) considered safe for compost [28].

On the other hand, it is noteworthy that the Composter environment performed, in terms of biodegradation activity, similarly to an industrial composting plant; indeed, in a short time (less than 3 months), it demonstrated to yield a mature and safe compost, for plants. Compost showed a sub-acid reaction ( $\mathrm{pH} 5.90)$ and low EC $\left(1.23 \mathrm{dS} \mathrm{m}^{-1}\right)$; moreover, it reached a high biological stability; in fact, after 45 days, it showed a very low dynamic respiration index (DRI $=139$ $\mathrm{mgO}_{2} \mathrm{~h}^{-1} \mathrm{~kg}^{-1} \mathrm{VS}$ ), with values largely below the threshold limit $\left(800 \mathrm{mgO}_{2} \mathrm{~h}^{-1} \mathrm{~kg}^{-1} \mathrm{VS}\right)$ set by the new European legislation [30] for high quality compost. The Composter is able to monitor in real time the DRI, thus allowing an objective evaluation on the compost quality achieved during the tests.

The quality of compost was also confirmed by the high GI index (102.8\%), determined on a significant sample collected random from the whole final biomass.

As regards disintegration test conducted under "home composting", (Fig. 13), a first visual inspection, to monitor the process, was done after 90 days only on PBSA neat specimens: although conducted in a less aggressive environment, PBSA neat specimens showed clear signs of disintegration.

Disintegration was then proven at the end of the trial (259th days) for the majority of specimens tested. In fact, PBSA, PBSA/HCe $20 \%$ and PBSA/HCa $20 \%$ specimens resulted completely disintegrated, leaving no visible residues in the biomass, sought after through an accurate manual sieving, while PBSA/HCa 5\% specimens, surprisingly, did not show any disintegration at all (Fig. 14). Such a different behavior could be explained by the different composition
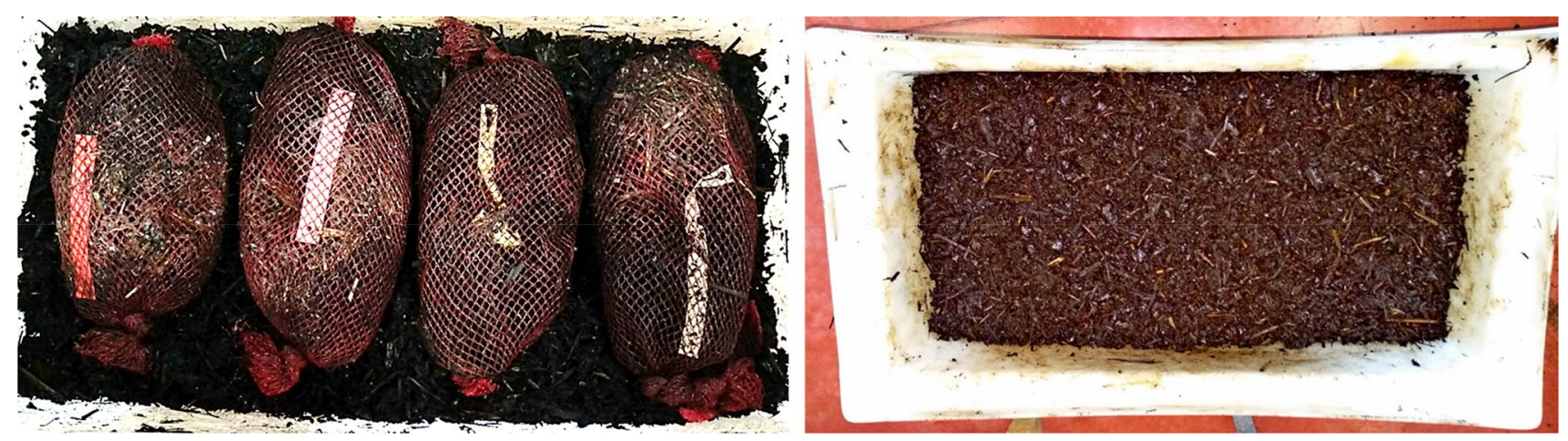

Fig. 10 Different specimens in separated PE net bags and buried into compost at room temperature (second curing phase, from 45 to 84 th days) 


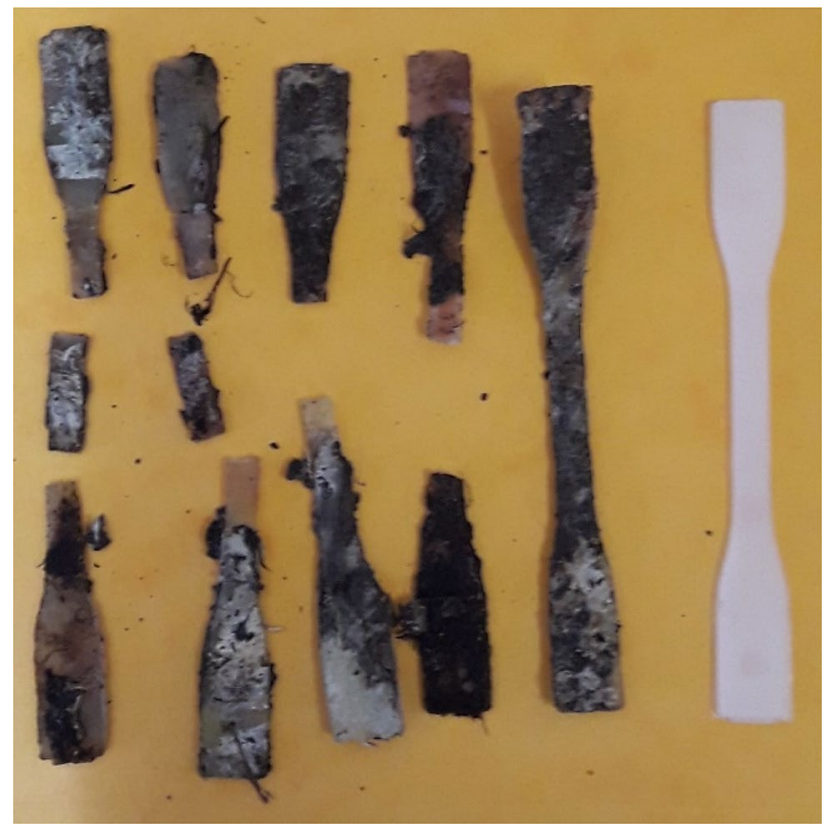

Fig. 11 Intermediate visual inspection on neat PBSA specimens after 20 days of industrial composting disintegration test occurred in Composter: on the right side the starting dog-bone specimens

of the compost to which the 5\% PBSA / HCa samples were exposed, as reported in Table 2.

These findings support the hypothesis that compost of different origin would have different performances, as a means of disintegration; therefore, particular attention must be paid to the quality of the compost used to perform the disintegration tests.

\section{Conclusions}

Blends based on PBSA and two different collagen hydrolysates, derived by alkaline (HCa) and enzymatic hydrolysis ( $\mathrm{HCe}$ ) of tannery byproducts, were investigated in terms of aerobic biodegradation and compostability. Most of the items produced by melt extrusion using $\mathrm{PBSA} / \mathrm{HC}$ blends up to $20 \mathrm{wt} . \% \mathrm{HC}$, in different form (pellets, films and molded dog-bone) resulted compostable and with good biodegradation rates even in home composting conditions.

All investigated PBSA/HC blends did not show negative effects on the germination of $L$. sativum seeds while showing appreciable amounts of important macro- and micro- nutrients for plants (mainly nitrogen).

In comparison to neat PBSA, the presence of $\mathrm{HCs}$ in the PBSA-based blends enhanced the biodegradation rate in the composting tests carried at $58{ }^{\circ} \mathrm{C}$. While, at $25{ }^{\circ} \mathrm{C}$, the different secondary structure and free amino acid content of the two hydrolysates leads to a different behavior of the blends, showing for the blends containing $20 \mathrm{wt} \% \mathrm{HCe}$ a lower biodegradation rate compared to neat PBSA and PBSA/ HCa blends.

In conclusion, the developed PBSA/HC blends appear a sustainable opportunity for valorizing by-products of the tanning industry in the production of biodegradable/compostable items with fertilizing properties, given the presence of HC, suitable for applications in plant nursery as mulch films or molded products (plant pots, small containers). 
Fig. 12 Dog-bone specimens after 84 days $(30+54$ days of thermal and mesophilic phases, respectively) of industrial composting disintegration test

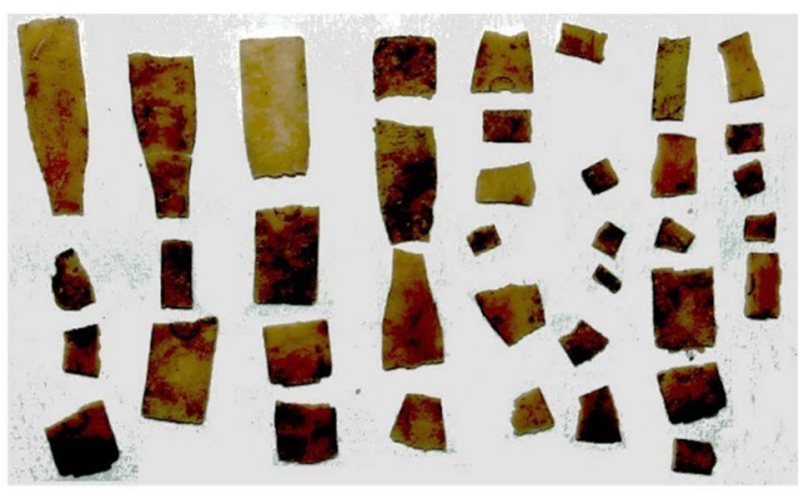

PBSA neat

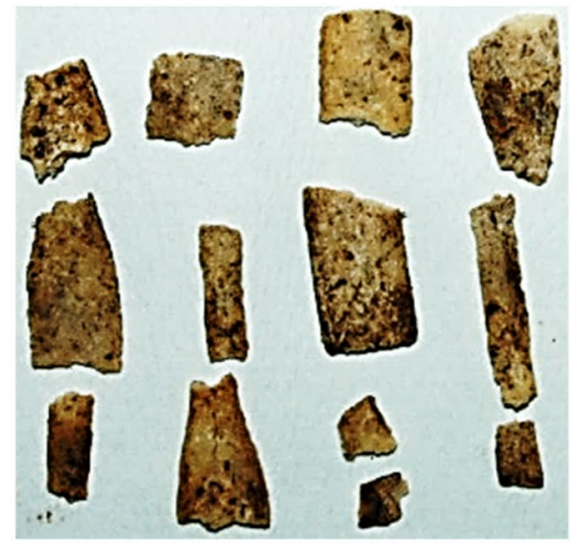

PBSA/HCa 5\%

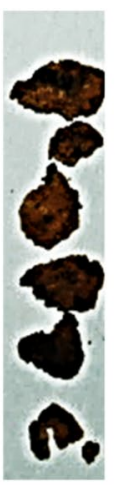

PBSA/HCe 20\%

Table 7 Quantification of plastic residues in compost and evaluation of some quality parameters of the compost sampled in the area where specimens disintegrated during the "Industrial composting" disintegration test

\begin{tabular}{lcrll}
\hline Sample & Residues, $\%$ & GI, $\%$ & $\mathrm{pH}$ & EC, $\mathrm{dS} \mathrm{m}^{-1}$ \\
\hline PBSA neat & 86.4 & 92.6 & 6.53 & 1.096 \\
PBSA/HCe 20\% & 6.0 & 99.1 & 6.65 & 1.186 \\
PBSA/HCa 5\% & 54.6 & 102.8 & 6.49 & 1.089 \\
PBSA/HCa 20\% & 11.4 & 87.5 & 6.65 & 0.965 \\
\hline
\end{tabular}



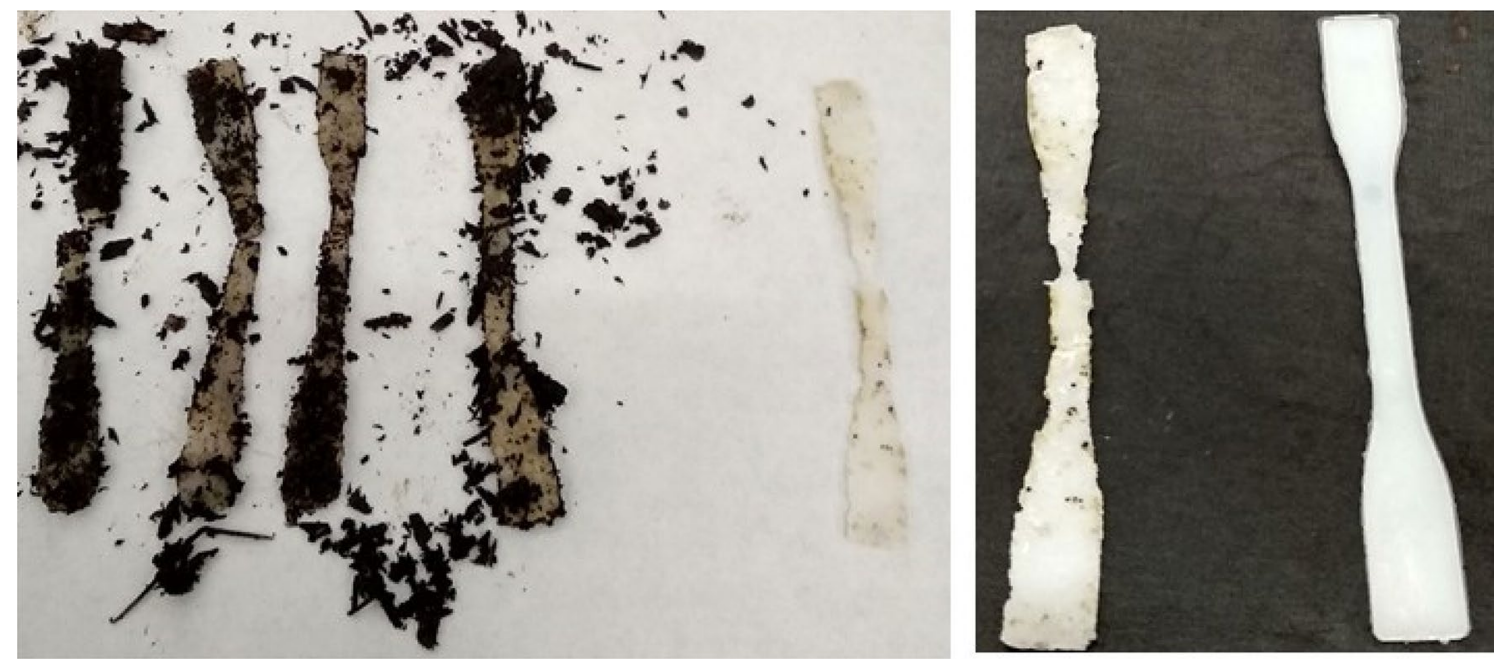

Fig. 13 First visual inspection of neat PBSA specimens after 90 days of home composting disintegration test

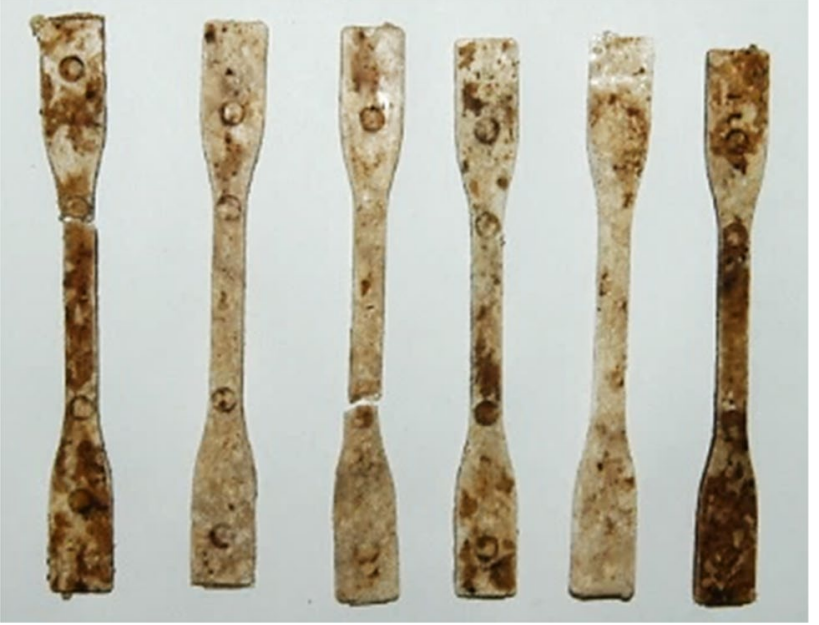

Fig. 14 Specimens of PBSA/HCa 5\% after 259 days of home composting disintegration test

Acknowledgements The authors would like to thank Dr. Francesco Castellani for his valuable support in the design, implementation and development of the Composter.

Funding Open access funding provided by Università di Pisa within the CRUI-CARE Agreement.

Open Access This article is licensed under a Creative Commons Attribution 4.0 International License, which permits use, sharing, adaptation, distribution and reproduction in any medium or format, as long as you give appropriate credit to the original author(s) and the source, provide a link to the Creative Commons licence, and indicate if changes were made. The images or other third party material in this article are included in the article's Creative Commons licence, unless indicated otherwise in a credit line to the material. If material is not included in the article's Creative Commons licence and your intended use is not permitted by statutory regulation or exceeds the permitted use, you will need to obtain permission directly from the copyright holder. To view a copy of this licence, visit http://creativecommons.org/licenses/by/4.0/.

\section{References}

1. European Commission, A European Strategy for Plastics in a Circular Economy, COM(2018) 28 final, 16.1.2018 Brussels.

2. Barrena R, Gea T, Ponsá S, Ruggieri L, Artola A, Font X, Sánchez A (2011) Compost Sci Uti 19(2):105. https://doi.org/10.1080/ 1065657X.2011.10736985

3. Lucas N, Bienaime C, Belloy C, Queneudec M, Silvestre F, NavaSaucedo JE (2007) Chemosphere 73:429

4. Fujimaki T (1998) Polym Degrad Stab 59:209. https://doi.org/10. 1016/S0141-3910(97)00220-6

5. Mitchell M, Ryder T, Hirt D (2017) Degradation of PBSA in water. California USA, SPE ANTEC, p 426

6. Ratto JA, Stenhouse PJ, Auerbach M, Mitchell J, Farrell R (1999) Polymer 40:6777. https://doi.org/10.1016/S0032-3861(99) 00014-2

7. Takiyama E, Fujimaki T, Seki S, Hokari T, Hatano Y. Method for manufacturing biodegradable high molecular aliphatic polyester (1994) US Patent 5,310,782

8. Nishioka M, Tuzuki T, Wanajyo Y, Oonami H, Horiuchi T (1994) In: Doi Y, Fukuda K (eds) Biodegradable Plastics and Polymers, Biodegradation of BIONOLLE Elsevier, London, https://doi. org/https://doi.org/10.1016/B978-0-444-81708-2.50069-5

9. Steeves DM, Farrell R, Ratto JA (2007) J Biobased Mater Bioenergy 1:94

10. Wang XL, Yang KK, Wang YZ (2003) J Macromol Sci Polym Rev 43:385. https://doi.org/10.1081/MC-120023911

11. Seggiani M, Altieri R, Puccini M, Stefanelli E, Esposito A, Castellani F, Stanzione V, Vitolo S (2018) Polym Degrad Stab 150:13. https://doi.org/10.1016/j.polymdegradstab.2018.02.001

12. Seggiani M, Altieri R, Esposito A, Cinelli P, Lazzeri A (2021) J Polym Environ 29:392. https://doi.org/10.1007/ s10924-020-01880-y

13. Castellani F, Esposito A, Stanzione V, Altieri R, Analysis of emissions from lab-scale composting equipment: data for a sustainability challenge, In: Proceedings of the 14th International Conference 
on Environmental Science and Technology, CEST 2015, (2016) 2:1346

14. Fujimaki T (1998) Polym Degrad Stab 159:209. https://doi.org/ 10.1016/S0141-3910(97)00220-6

15. PTT MCC Biochem. http://www.pttmcc.com/new/faq.php (accessed 29th August 2020)

16. Malz F, Arndt J-H, Balko J, Barton B, Büsse T, Imhof D, Pfaendner R, Rode K, Brüll R (2021) J Chromatogr A 1638:461819

17. http://www.pttmcc.com/new/download/BioPBS_FD92PM_and_ FD92PB_Technical_Data_Sheet_for_film(2).pdf (accessed 27th January 2021)

18. US-EPA Method 3051A, Microwave assisted acid digestion of sediments, sludges, soils and oils. Test Methods for Evaluating Solid Waste, US Environmental Protection Agency, Washington, DC, USA, (2007) 3rd edition

19. Zucconi F, Pera A, Forte M, de Bertoldi M (1981) Biocycle 22:54

20. UNI EN 13432 (2000) Packaging - Requirements for packaging recoverable through composting and biodegradation - Test scheme and evaluation criteria for the final acceptance of packaging

21. UNI EN ISO 14855-1, Determination of the ultimate aerobic biodegradability of plastic materials under controlled composting conditions - Method by analysis of evolved carbon dioxide - Part 1: General method. International Organization for Standardization (2012)

22. Castellani F, Esposito A, Stanzione V, Altieri R (2016). Adv Mater Sci Eng. https://doi.org/10.1155/2016/6909283
23. Chilosi G, Esposito A, Castellani F, Stanzione V, Aleandri MP, dell'Unto D, Tomassini A, Vannini A, Altieri R (2018) Waste Biomass Valorization 9:919. https://doi.org/10.1007/ s12649-017-9855-7

24. Australian Standards ${ }^{\circledR} 5810$. Biodegradable plastics - Biodegradable plastics suitable for home composting (2010)

25. UNI EN 14045, Packaging - Evaluation of the disintegration of packaging materials in practical oriented tests under defined composting conditions (2003)

26. Yamamoto-Tamura K, Hiradate S, Watanabe T, Koitabashi M, Sameshima-Yamashita Y, Yarimizu T, Kitamoto H (2015) AMB Expr 5:10. https://doi.org/10.1186/s13568-014-0088-X

27. Molina FV (2014) Soil Colloids. Boca Raton, CRC Press, London. https://doi.org/10.1201/b15349

28. DL 75:2010. Decreto Legislativo 29 aprile 2010, n. 75 of Italian Republic "Riordino e revisione della disciplina in materia di fertilizzanti', a norma dell' articolo 13 della Legge 7 luglio 2009 n.88, Gazzetta Ufficiale n. 121 - Supplemento Ordinario n.106, Roma, May 26th.

29. Salomez M, George M, Fabre P, Touchaleaume F, Cesar G, Lajarrige A, Gastaldi E (2019) Polym Degrad Stab 167:102. https://doi. org/10.1016/j.polymdegradstab.2019.06.025

30. EU Regulation 1009 of the European Parliament and of the Council (2019)

Publisher's Note Springer Nature remains neutral with regard to jurisdictional claims in published maps and institutional affiliations. 